\title{
The molecular evolutionary characteristics of new isolated H9N2 AIV from East China and the function of vimentin on virus replication in MDCK cells
}

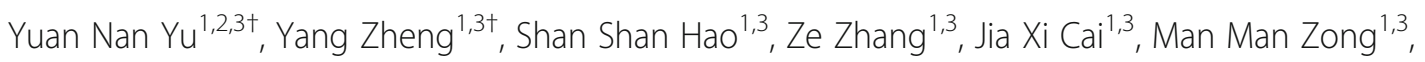
Xiu Li Feng ${ }^{1,3^{*}}$ (D) and Qing Tao Liu ${ }^{2^{*}}$

\begin{abstract}
Background: The low pathogenic H9N2 AIV caused the serious impact on the poultry industry and public safety. Our purpose was to investigate the molecular evolutionary characteristics of the new isolated H9N2 virus and investigate the intracellular target protein of H9N2 AIV replication in sensitive cells.

Methods: AIV A/chicken/Shandong/LY1/2017 (H9N2) was isolated from the cloaca of the healthy chicken in Shandong, and the full-length eight gene segments of this isolated H9N2 AIV were amplified by RT-PCR and analyzed. MDCK cells were used as the target cell model, and VOPBA assay and LC-MS/MS were carried out to identify the virus-binding protein of H9N2 AIV. MDCK cells were pre-treated with the special antibody and siRNA, and treated with H9N2 AIV to detect the virus replication. Additionally, Vimentin-pcDNA3.0 was successfully constructed, and transinfected into MDCK cells, and then H9N2 AIV mRNA was detected with RT-PCR.
\end{abstract}

Results: Phylogenetic analysis revealed that HA, NA, PB2, PB1, PA, NP and M seven genes of the isolated H9N2 AIV were derived from A/Chicken/Shanghai/F/98, while NS gene was derived from A/Duck/Hong Kong/Y439/97. The cleavage site sequence of HA gene of the isolated H9N2 AIV was a PARSSR G pattern, and the left side sequence (224 229) of receptor binding site was NGQQGR pattern, which were similar to that of A/Chicken/Shanghai/F/98. Following VOPBA assay, we found one protein of about 50KDa binding to H9N2 AIV, and the results of LC-MS/MS analysis proved that vimentin was the vital protein binding to H9N2 AIV. The pre-incubation of the specific antibody and siRNA decreased the viral RNA level in MDCK cells treated with H9N2 AIV. Furthermore, we found that over-expressed vimentin increased H9N2 AIV replication in MDCK cells.

(Continued on next page)

\footnotetext{
* Correspondence: xiulifeng@njau.edu.cn; taoqingliu2013@163.com

†Yuan Nan Yu and Yang Zheng contributed equally to this work.

${ }^{1}$ Key Laboratory of Animal Microbiology of China's Ministry of Agriculture,

College of Veterinary Medicine, Nanjing Agricultural University, Nanjing

210095, China

${ }^{2}$ Institute of Veterinary Medicine, Jiangsu Academy of Agricultural Sciences,

Nanjing 210014, China

Full list of author information is available at the end of the article
}

(c) The Author(s). 2020 Open Access This article is licensed under a Creative Commons Attribution 4.0 International License, which permits use, sharing, adaptation, distribution and reproduction in any medium or format, as long as you give appropriate credit to the original author(s) and the source, provide a link to the Creative Commons licence, and indicate if changes were made. The images or other third party material in this article are included in the article's Creative Commons licence, unless indicated otherwise in a credit line to the material. If material is not included in the article's Creative Commons licence and your intended use is not permitted by statutory regulation or exceeds the permitted use, you will need to obtain permission directly from the copyright holder. To view a copy of this licence, visit http://creativecommons.org/licenses/by/4.0/ The Creative Commons Public Domain Dedication waiver (http://creativecommons.org/publicdomain/zero/1.0/) applies to the data made available in this article, unless otherwise stated in a credit line to the data. 
(Continued from previous page)

Conclusions: These findings suggested that the isolated H9N2 AIV might be a recent clinical common H9N2 strain, and vimentin protein might be one vital factor for H9N2 AIV replication in MDCK cells, which might be a novel target for design and development of antiviral drug.

Keywords: H9N2 AIV, Phylogenetic characteristics, Molecular variations, Vimentin, siRNA, Virus replication

\section{Background}

H9N2 subtype avian influenza virus (AIV) has become responsible for the increasingly serious influence on poultry production and human health. Since 1994, H9N2 AIV was prevalent rapidly in many chicken farms and waterfowl populations, and became the most popular subtype of AIV in China [1-4]. The phylogenetic analysis of early isolates' genes showed that H9N2 subtype had been circulating as a mainland China strain $[5,6]$. Also, it was reported that the antigenicity of isolated H9N2 strains was different from that of vaccine strain in Guangdong, China [7]. Epidemiological studies showed that Neuraminidase (NA) gene of H7N9 influenza virus was homologous to that of H10N9 AIVs (A/chicken/Jiangsu/RD5/2013) isolated from the local live poultry market, whose internal genes were offered from the current popular H9N2 subtype AIV [8, 9]. Besides, H9N2 subtype AIV was the donor for the internal gene of the new H10N8 virus infected people [10, 11]. Similarly, some isolated H9N2 viruses shared human virus-like receptor specificity and substitution resembling human virus in the hemagglutinin (HA) site in Hong Kong $[12,13]$. Pig introduced by $\mathrm{H} 9$ viruses would increase the risk of generating mammalian-adapted or reassorted variants, which might be potentially infectious to humans [14]. Therefore, it was important to investigate H9N2 AIV surveillance for the development of poultry industry and human safety.

Influenza viruses internalized and became into the early endosomal Endosomes (EEs) through the binding of HA protein with membrane surface receptor sites Nacetyl neuraminic acid (Neu Ac) and hydroxyacetyl neuraminic acid (Neu Gc), and then developed the late endosomal Endosomes (LEs) [15]. The viral genome was transported to the nucleus after recognition with the cell transporter, and the viral transcription and replication process was initiated [16]. The genetically similar H9N2 influenza A viruses presented the high or low pathogenicity in mice, in which multiple amino acid differences in PB2 gene may be responsible for the pathogenic difference of AIV for mice [17]. It has been reported that the variations of $\mathrm{E} 627 \mathrm{~K}$ and $\mathrm{D} 701 \mathrm{~N}$ in the PB2 gene might cause AIV through the species innate barrier to infect mammals, and the enhance virulence of the mutated AIV [18].
It was important to investigate AIV attachment to trachea in many avian species [19]. AIVs mainly attached to $\alpha 2,3$-linked SA, but also to combinations of $\alpha 2,3$ - and $\alpha 2,6$-linked SA [20]. Kim found the differential influenza receptor expression pattern in mouse and human brains, and a disparity between influenza receptor distribution and regions with actual influenza infection [21]. To explore the possible intracellular receptor of AIV during virus infection and replication, in this paper, we employed the viral overlay protein binding assay to identify one receptor binding to H9N2 subtype AIV, and adopted the specific antibody block, siRNA and overexpression to study the effect of vimentin on H9N2 AIV replication in the sensitive cells.

\section{Methods and materials}

Virus, cells, and antibodies

H9N2 AIV used in this study was isolated from the cloaca of the healthy chicken in Shandong 2017, which was collected as samples of routinely ongoing surveillance. The hemagglutination inhibition with the special antibody confirmed that the isolate might be H9N2 subtype AIV. The virus was thrice propagated in 9-day-old specific-pathogen-free (SPF) embryonated chicken eggs, and then gene fragments were sequenced and comparatively analyzed. Madin-Darbycanine kidney (MDCK) cells were maintained in Dulbecco modified Eagle medium (DMEM) supplemented with 10\% fetal bovine serum (FBS) and $5 \% \mathrm{CO}_{2}$ at $37^{\circ} \mathrm{C}$.

Anti-vimentin monoclonal antibody was purchased from Abcam (ab45939) and anti-hemagglutinin polyclonal antibody was purchased from Jianchun Biotechnology (Nanjing). Anti- Glycerophosphate dehydrogenase (GAPDH) antibody (ab8245) was purchased from Abcam. Alkaline phosphatase conjugated goat anti-rabbit IgG and HRPconjugated goat anti-mouse IgG secondary antibody was purchased from Univ Biotechnology (Shanghai). Vimentin siRNA was purchased from Santa Cruz (sc-156,015).

\section{RT-PCR}

Based on the whole genome sequence of H9N2 AIV published in GenBank database of US National Center for Biotechnology Information (NCBI), showed in Table $\mathrm{S} 1$, the primer sequences of eight gene fragments of the H9N2 subtype AIV were designed, as shown in Table S2. Following Trizol instruction, the total RNAs were 
extracted from the allantoic fluids containing the isolated H9N2 AIV. According to the PrimeScriptTMRT Master Mix reverse transcription kit, cDNA was used as templates for polymerase chain reaction (PCR) amplification for eight genes fragments of the isolated virus.

\section{Gene sequencing and phylogenetic analysis}

To eliminate the nucleotide acids error of eight genes in cDNA clones obtained using RT-PCR, five samples for each gene were sequenced by Nanjing Qing Ke biological company (Nanjing, China), and eight genes fragments were amplified. Also, MEGA5.3 was used to diagram the phylogenetic tree of each gene fragment [22], and to investigate the genetic evolution relationship between $\mathrm{A} /$ chicken/Shandong/LY1/2017 and other H9N2 strains.

\section{Viral overlay protein binding assay (VOPBA)}

The samples of MDCK cells were obtained to extract all the intracellular proteins after ultrasonication and proteolysis. The collected proteins samples were analyzed with $12 \%$ SDS-PAGE, and transferred onto polyvinylidene fluoride (PVDF) membranes. After blocked, the transferred membranes were incubated with 1 multiplicity of infection (MOI) H9N2 subtype AIVs, and then incubated with rabbit polyclonal antibody special to HA protein of H9N2 AIV, and then incubated with goat anti-rabbit IgG secondary antibody. After screened, the results were developed with high resolution image acquisition system.

\section{Protein mass spectrometry sequencing}

Simultaneously, the proteins samples were analyzed and stained with Coomassie staining, and the bands equivalent to the above western blot of the major virus binding band were recovered and analyzed for liquid chromatography tandem mass spectrometry (LC-MS/MS) analysis by Shanghai Zhongke Xinsheng Life Biotechnology Co., Ltd. (China, Shanghai). Simply, after reduction and alkylation, Trypsin was added into the examined samples to enzymatic hydrolysis for $20 \mathrm{~h}$ at $37^{\circ} \mathrm{C}$. After desalination and freeze-drying, the samples were dissolved in $0.1 \%$ FA solution, and then performed on Trap column for mass spectrometry. After MS2 scan, the raw files were obtained and searched in the related databases through Mascot 2.2 software. The detailed search parameters were showed in Table S3.

\section{Inhibition of H9N2 infection by Vimentin antibody}

MDCK cells were incubated with $100 \mu \mathrm{g} / \mathrm{mL}$ antiVimentin antibody (ab45939) or rabbit IgG control at $37^{\circ} \mathrm{C}$ for $2 \mathrm{~h}$. After washing twice with phosphate buffer saline (PBS), the incubated MDCK cells were infected by 0.1 MOI $\mathrm{H} 9 \mathrm{~N} 2$ virus at $37^{\circ} \mathrm{C}$ for $1.5 \mathrm{~h}$, and cultured with DMEM for $36 \mathrm{~h}$. Following Trizol instruction, the total RNAs of MDCK cells were extracted to be usaed as templates for RT-qPCR. The primers used for RT-qPCR were showed in Table S4. GAPDH was chosen as a internal gene control. The rabbit IgG incubated cells were used as a control for each comparison.

\section{RNA interference and H9N2 virus infection}

MDCK cells in 12-well plate were transfected with vimentin siRNA and control siRNA according to Lipofectamine-3000 (Invitrogen) protocol. After $24 \mathrm{~h}$, the transfected MDCK cells were infected with $0.1 \mathrm{MOI}$ H9N2 AIV at $37^{\circ} \mathrm{C}$ for $1 \mathrm{~h}$, and were cultured with DMEM for $36 \mathrm{~h}$, and then were collected to detect the vimentin mRNA and viral mRNA levels by RT-qPCR. Also, the knock-down expressed vimentin proteins were detected by western blot with vimentin antibody (ab45939) as the previous reported [23]. Control siRNA was used for control treatment.

\section{Over-expression of Vimentin and H9N2 virus infection}

According to the published sequence NM_001287023.1 in Genbank database from NCBI, the primers of Vimentin

Table 1 Homology between the gene segments of LY1/ and that of some H9N2 isolates

\begin{tabular}{|c|c|c|c|c|c|c|c|c|c|c|c|c|}
\hline \multirow[t]{2}{*}{ LY1 } & \multirow{2}{*}{$\begin{array}{l}\text { Region of } \\
\text { comparison } \\
\text { (Nucleotide) }\end{array}$} & \multicolumn{11}{|c|}{$\%$ Homology with H9N2 virus } \\
\hline & & JS7 & JSC1 & $\mathrm{HBC} 1$ & F98 & G9 & BJ1 & Y280 & SD696 & Wis66 & Y439 & G1 \\
\hline $\mathrm{HA}$ & $57-1619$ & 99.9 & 99.9 & 99.3 & 99.5 & 95.3 & 96.7 & 94.8 & 96.2 & 82.3 & 84.8 & 91.2 \\
\hline NA & $20-1412$ & 99.9 & 99.5 & 99.2 & 97.5 & 93.8 & 96 & 96.8 & 96.3 & 86.9 & 88.4 & 91.9 \\
\hline PB2 & $49-2284$ & 99.6 & 99.7 & 99.4 & 98.8 & 86.3 & 92.4 & 91.6 & 92 & 83.9 & 92.5 & 86.1 \\
\hline PB1 & $25-2233$ & 99.8 & 99.9 & 99.2 & 98.8 & 91.9 & 91.9 & 90.9 & 91.6 & 88.3 & 91.4 & 92.1 \\
\hline PA & $53-2151$ & 99.7 & 99.9 & 99.4 & 98.8 & 89.3 & 91.2 & 89.9 & 90.1 & 86.9 & 91.7 & 92.1 \\
\hline NP & 56-1501 & 99.7 & 100.0 & 99.1 & 99 & 90.7 & 91.3 & 90.5 & 90.7 & 89 & 95 & 93.3 \\
\hline M & 36-995 & 100.0 & 100.0 & 100.0 & 99.1 & 98.2 & 97.7 & 98.4 & 98.1 & 91.6 & 92.3 & 95.7 \\
\hline NS & $41-851$ & 99.9 & 100.0 & 99.4 & 90.4 & 90.8 & 91.6 & 90.8 & 91.2 & 92.1 & 96.4 & 90.6 \\
\hline
\end{tabular}

Note: LY1: A/chicken/Shandong/LY1/2017; JS7: A/chicken/Jiangsu/7/2002; JSC1: A/swine/Jiangsu/C1/2008; HBC1: A/chicken/Hubei/C1/2007; F98: A/Chicken/ Shanghai/F/98; G9:A/Chicken/Hong Kong/G9/97; BJ1: A/Chicken/Beijing/1/94; Y280:A/Duck/Hong Kong/Y280/97; SD696: A/Chicken/Shandong/6/96; Wis66:A/ Turkey/Wisconsin/66; Y439: A/Duck/Hong Kong/Y439/97; G1: A/Duck/Hong Kong/Y439/97 

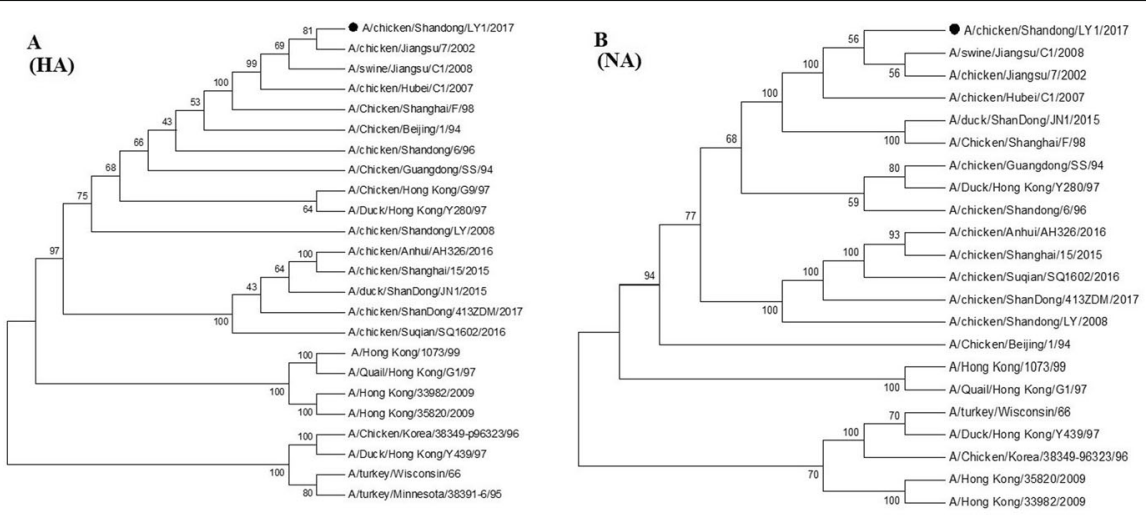

$\underset{\text { (PB2) }}{\mathrm{C}}$

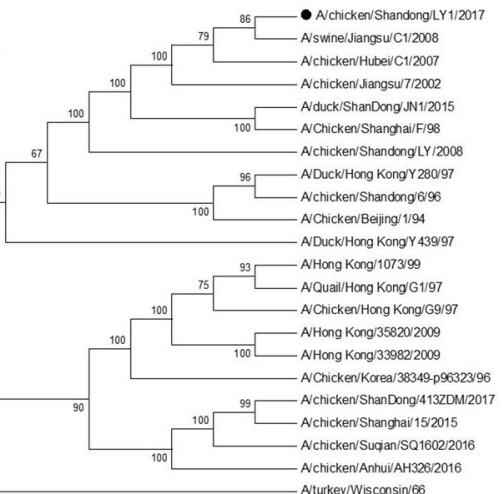

E
(PA)
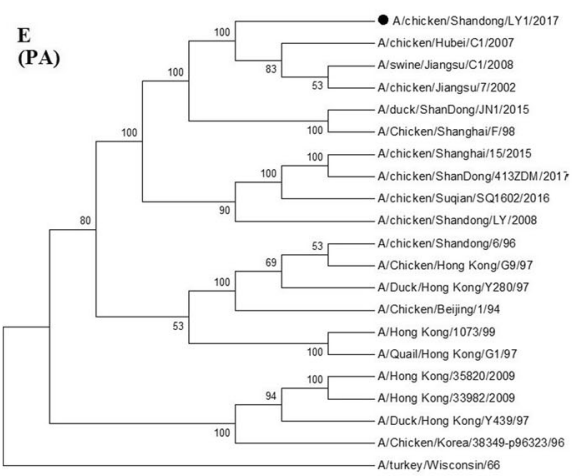
A/turkey Wisconsin' 66

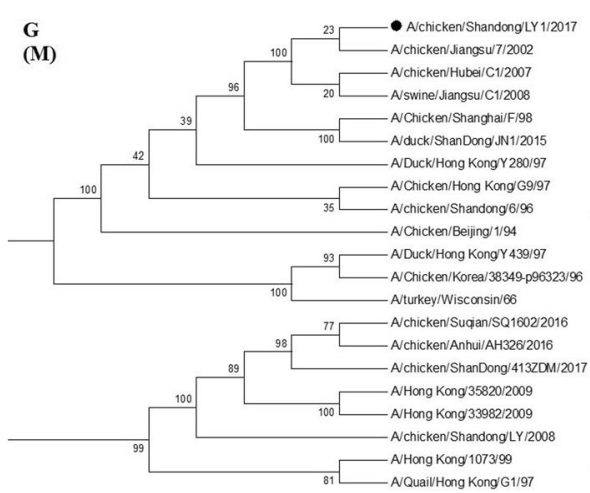

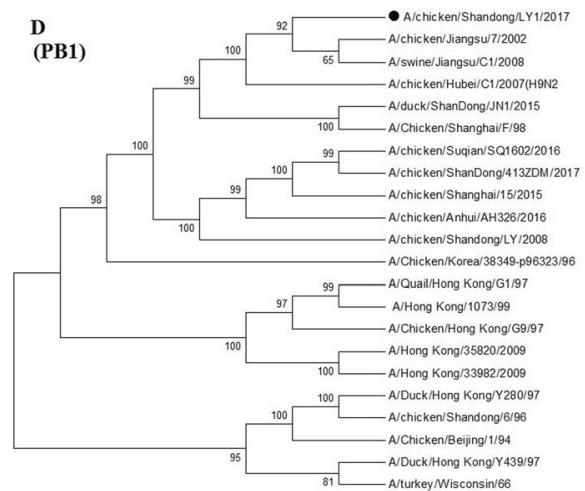
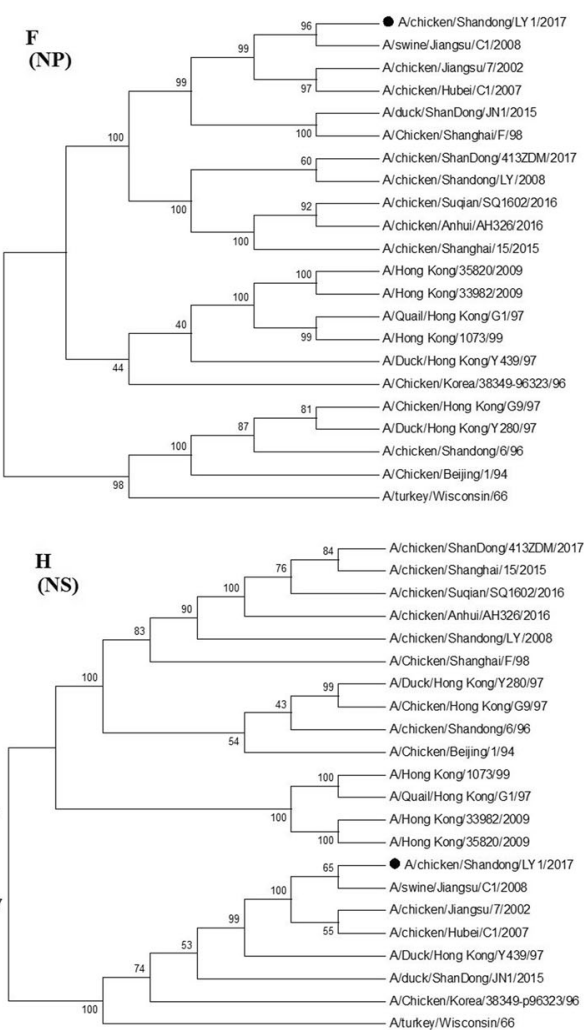

Fig. 1 (See legend on next page.) 
(See figure on previous page.)

Fig. 1 Phylogenetic trees for eight gene segments of LY1 (H9N2) virus. Nucleotides 57-1619 (1563 bp) of HA gene, 20-1412 (1393 bp) of NA gene, 49-2284 (2235 bp) of PB2 gene, 25-2233 (2209 bp) of PB1 gene, 53-2151 (2098 bp) of PA gene, 56-1501 (1445 bp) of NP gene, 36-995 (960 bp) of M gene and 41-851 (811 bp) of NS gene were analyzed. The trees were generated and edited with MEGE 5.0 software. Horizontal distances were proportional to the minimum number of nucleotide differences required to join nodes. All the sequences including LY1 strain can be found in Genbank (accession number available upon request)

were designed by Primer Premier 6.0, as showed in Table S5. Total RNA was extracted from MDCK cells by Trizol (Takara), and cDNA was synthesized by Reverse transcription Kit (Abm-Zhengjiang) to amplify vimentin gene. After sequenced, vimentin gene was ligated into pcDNA-3.0 vector using EcoR I and Hind III restriction sites to construct the eukaryotic expression vector vimentin-pcDNA3.0.

Vimentin-pcDNA3.0 was transfected by using Lipofectamine-3000 (Invitrogen) in 6-well plate, and vector pcDNA3.0 transfected MDCK cells were used as control. At $60 \mathrm{~h}$ post-transfection, vimentin mRNA in the transfected MDCK cells were detected by RT-qPCR, and the expression of vimentin proteins were checked by western blot with vimentin antibody (ab45939). Additionally, at $24 \mathrm{~h}$ post-transfection, the Vimentin-pcDNA3.0 transfected cells were incubated 0.1 MOI H9N2 AIVs for $1 \mathrm{~h}$ at $37^{\circ} \mathrm{C}$, and cultured in DMEM with $10 \%$ FBS for $36 \mathrm{~h}$ to detect $\mathrm{H} 9 \mathrm{~N} 2$ virus units by RT-qPCR.

\section{Statistical analysis}

Results were illustrated in bar graphs as means \pm standard deviation (SD) of three independent experiments. The statistical significances were analyzed by $t$-test or one-way ANOVA with significantly difference less than 0.05 .

\section{Results}

\section{Phylogenetic analysis of the isolated H9N2 AIV}

To verify the detailed subtype,, the isolate were obtained after thrice propagated in 9-day-old SPF embryonated chicken eggs for comparative analysis of gene fragments. Eight genes fragments of AIV (A/chicken/Shandong/ LY1/2017, abbreviated as LY1) were amplified, respectively, and the full length genome of LY1 was obtained (Table 1), which were available in GenBank accession numbers MH018674 - MH018681.

To examine the molecular evolutionary relationship of this isolate virus, the phylogenetic comparisons of eight gene segments were carried out among LY1 and other H9N2 AIVs. The phylogenetic trees showed that HA, NA, PB2, PB1, PA, NP and M seven genes of LY1 were derived from A/Chicken/Shanghai/F/98 (F98)(Fig. 1a g), whereas NS genes of the isolated virus shared a common ancestor with that of A/Duck/Hong Yong/Y439/97 virus (Y439) (Fig. 1h).

\section{Homology analysis of LY1 H9N2 AIV}

It was noteworthy that the whole genome of LY1 had the highest homologies to that of the three isolates $\mathrm{A} /$ chicken/Jiangsu/7/2002 (JS7), A/swine/Jiangsu/C1/2008 (JSC1) and A/chicken/Hubei/C1/2007 (HBC1), in which homologies between eight full-length segments of LY1 and those of three viruses ranged from 99.1 to $100 \%$ (Table 1). Furthermore, the homologies in HA, NA, PB2, PB1, PA, NP and M seven genes between LY1 and F98 were from 97.5 to $99.5 \%$, and NS gene between LY1 and Y439 was $96.4 \%$ (Table 1). These results suggested that LY1 might be a recent clinical common H9N2 strain.

\section{Molecular features of HA in LY1 strain}

The cleavage site sequence of LY1 strain was a PARSSR $\downarrow G$ pattern, which was consistent with that of the Y280 subline (Clade h9.4.2, Table 2). Furthermore, three recently isolates of JS7, JSC1 and $\mathrm{HBC} 1$ and three referred strains of Y280, BJ1 and F98 strains were used as the reference strains to comparatively analyze the mutation of the receptor binding site of HA gene of LY1. The results showed that there no mutated amino acid in receptor binding sites of HA genes presented among LY1, JS7, JSC1 and HBC1 isolates (Table 3). The left side sequence $(224 \sim 229)$ of receptor binding site of HA

Table 2 Connecting-peptide at the cleavage site of H9N2 subtype AIV strains

\begin{tabular}{lll}
\hline Virus & Clade & Connecting-peptide at the cleavage site of HA \\
\hline LY1 & $h 9.4 .2$ & PARSSR $\downarrow G$ \\
JS7 & $h 9.4 .2$ & PARSSR $\downarrow$ \\
JSC1 & $h 9.4 .2$ & PARSSR $\downarrow G$ \\
HBC1 & $h 9.4 .2$ & PARSSR $\downarrow G$ \\
F98 & $h 9.4 .2$ & PARSSR $\downarrow G$ \\
G9 & $h 9.4 .2$ & PARSSR $\downarrow G$ \\
BJ1 & $h 9.4 .2$ & PARSSR $\downarrow G$ \\
Y280 & $h 9.4 .2$ & PARSSR $\downarrow G$ \\
SD696 & $h 9.4 .2$ & PARSSR $\downarrow G$ \\
Wis66 & $h 9.1$ & PAVSSR $\downarrow G$ \\
Y439 & $h 9.3$ & PAASNR $\downarrow G$ \\
G1 & $h 9.4 .1$ & PSRSSR $\downarrow G$ \\
\hline
\end{tabular}

Note: LY1: A/chicken/Shandong/LY1/2017; JS7: A/chicken/Jiangsu/7/2002; JSC1: A/swine/Jiangsu/C1/2008; HBC1: A/chicken/Hubei/C1/2007; F98: A/Chicken/ Shanghai/F/98; G9:A/Chicken/Hong Kong/G9/97; BJ1: A/Chicken/Beijing/1/94; Y280:A/Duck/Hong Kong/Y280/97; SD696: A/Chicken/Shandong/6/96; Wis66:A/ Turkey/Wisconsin/66; Y439:; G1: A/Duck/Hong Kong/Y439/97 
Table 3 Analysis of Receptor Binding Sites in HA Gene in H9N2 AlVs

\begin{tabular}{|c|c|c|c|c|c|c|c|c|c|}
\hline Strains & Left edge NGLQGR (224 229) & $101 \mathrm{~N}$ & $153 \mathrm{~W}$ & $155 \mathrm{~T}$ & $183 \mathrm{~N}$ & $190 \mathrm{~T}$ & $194 \mathrm{~L}$ & $195 Y$ & Left edge GTSKA $(138 \sim 142$ \\
\hline Y280 & + & + & + & + & + & + & + & + & + \\
\hline BJ1 & NGQQGR & + & + & + & + & V & + & + & + \\
\hline F98 & NGQQGR & + & + & + & + & A & + & + & + \\
\hline JS7 & NGQQGR & + & + & + & + & V & + & + & + \\
\hline JSC1 & NGQQGR & + & + & + & + & V & + & + & + \\
\hline $\mathrm{HBC1}$ & NGQQGR & + & + & + & + & V & + & + & + \\
\hline LY1 & NGQQGR & + & + & + & + & V & + & + & + \\
\hline
\end{tabular}

Note: LY1: A/chicken/Shandong/LY1/2017; Y280:A/Duck/Hong Kong/Y280/97; BJ1: A/Chicken/Beijing/1/94; F98: A/Chicken/Shanghai/F/98; JS7: A/chicken/Jiangsu/7/ 2002; JSC1: A/swine/Jiangsu/C1/2008; HBC1: A/chicken/Hubei/C1/2007. " + ": With the same amino acid sites

gene in LY1 was NGQQGR pattern, namely, $Q$ at position 226, consistent with that of F98 and BJ1 strains. Besides, the amino acid at 190 site of HA gene in the isolate was $\mathrm{V}$, which was same to that of BJ1 strain but different to that of F98 strain.

The potential glycosylation sites analysis on the HA of LY1 showed that LY1 had seven potential glycosylation sites at the same positions as those of three recently isolates, which were less than that of three typical strains (Table 4). Compared with the three typical strains Y280, BJ1 and F98, the amino acid at position 218 of HA gene in LY1 was T, resulting in the glycosylation site deletion at position 218. Furthermore, we found that the amino acid at position 145 of HA gene of LY1 had mutated to be N, resulting in a new glycosylation site NGT at this position.

\section{Molecular characteristics of NA in LY1 strain}

It was observed that the deletions in the stalk and potential N-glycosylation sites of NA gene in LY1 were same to that of F98, JS7, JSC1 and HBC1 strain (Table 5). Compared to that of $\mathrm{BJ} 1$, the deletion of three amino acids ITE at position 62 to 64 in NA gene leaded to the deletion of glycosylation sites at position 61 in NA protein of LY1 strain. Unexpectedly, one amino acid mutant from NST to NNT at position 69 were occurred in NA protein of three recently isolates JS7, JSC1 and $\mathrm{HBC1}$, which did not change the glycosylation sites at position 69 in NA protein of these three isolates.

The receptor binding sites of NA protein in LY1 mainly existed at three positions, 367 KVDSRS 372, 400 SDNW 403 and 431 PQE 433. It was found that the KVDSRS pattern in NA protein of LY1, which was same to that of the three recently strains JS7, JSC1 and HBC1, and different to that of three typical strains F98, Y280 and BJ1 strains (Table 5).

\section{Identification of Vimentin as H9N2 AIV binding protein}

To identify the protein in MDCK cells involved in H9N2 virus attachment, we employed VOPBA with polyclonal antibody against HA protein of H9N2 virus, and found one strong binding-band with molecular mass about $50 \mathrm{KDa}$, in which the same bands appeared in the both parallel samples (Fig. 2a). Also, the equivalent protein bands with about $50 \mathrm{KDa}$ from duplicated coomassie blue gel was obtained to be analyzed for the binding protein by biotechnology company (Fig. 2b). The LC-MS/MS analysis spectrum for the band protein was showed in Fig. 2c. According to the value of UniquePepCount and molecular mass in the related databases through Mascot 2.2 software, the molecular weight of vimentin was $53.5 \mathrm{KDa}$, which was consistent with that of binding-band protein band, and the UniquePepCount of vimentin was 27

Table 4 Prediction of the potential glycosylation sites of HA protein in H9N2 AIVs

\begin{tabular}{|c|c|c|c|c|c|c|c|c|c|}
\hline Site Sequence Strains & 29 NST & 141 NVS & 145 NGT & 218 NRT & $298 \mathrm{NTT}$ & 305 NVS & 313 NCS & 492 NGT & 551 NGS \\
\hline Y280 & + & + & - & + & + & + & - & + & + \\
\hline BJ1 & + & $\mathrm{NVT}$ & - & + & + & + & - & + & + \\
\hline F98 & + & + & - & + & + & + & - & + & + \\
\hline JS7 & + & + & + & - & + & + & - & + & + \\
\hline JSC1 & + & + & + & - & + & + & - & + & + \\
\hline $\mathrm{HBC1}$ & + & + & + & - & + & + & - & + & + \\
\hline LY1 & + & + & + & - & + & + & - & + & + \\
\hline
\end{tabular}


Table 5 Amino acid sequence analysis of NA gene of AlV strains

\begin{tabular}{|c|c|c|c|c|c|c|c|c|c|c|c|}
\hline \multirow{3}{*}{$\begin{array}{l}\text { Site } \\
\text { Sequence }\end{array}$} & \multirow{3}{*}{$\begin{array}{l}\text { Deletion in the stalk } \\
62 \sim 64 \\
\text { ITE }\end{array}$} & \multicolumn{7}{|c|}{ Potential N-glycosylation sites } & \multicolumn{3}{|c|}{ Hemadsorbing sites } \\
\hline & & 61 & 69 & 86 & 146 & 200 & 234 & 402 & $367 \sim 372$ & $400 \sim 403$ & $431 \sim 433$ \\
\hline & & NIT & NST & NWS & NGT & NAT & NGT & NWS & KKDSRS & SDNW & PQE \\
\hline \multicolumn{12}{|l|}{ Strains } \\
\hline Y280 & + & - & + & + & + & + & + & + & KEDSRS & + & + \\
\hline BJ1 & - & + & + & + & + & + & + & + & + & + & + \\
\hline F98 & + & - & + & + & + & + & + & + & KKDSRS & + & + \\
\hline JS7 & + & - & NNT & + & + & + & + & + & KVDSRS & + & + \\
\hline $\mathrm{JSC} 1$ & + & - & NNT & + & + & + & + & + & KVDSRS & + & + \\
\hline $\mathrm{HBC} 1$ & + & - & NNT & + & + & + & + & + & KVDSRS & + & + \\
\hline LY1 & + & - & + & + & + & + & + & + & KVDSRS & + & + \\
\hline
\end{tabular}

Note:LY1: A/chicken/Shandong/LY1/2017; Y280:A/Duck/Hong Kong/Y280/97; BJ1: A/Chicken/Beijing/1/94; F98: A/Chicken/Shanghai/F/98; JS7: A/chicken/Jiangsu/7/ 2002; JSC1: A/swine/Jiangsu/C1/2008; HBC1: A/chicken/Hubei/C1/2007. "+": With the same amino acid sequence; "-": Without the same amino acid sequence

(Table 6), suggesting vimentin might be the protein binding to H9N2 AIV in MDCK cells.

The antibody against Vimentin inhibited H9N2 virus entry To determine the role of membrane vimentin protein in H9N2 virus entry, MDCK cells were preincubated with anti-vimentin antibody, and then infected with H9N2 AIV. The qPCR results showed that the viral RNA level was significant lower in anti-vimentin antibody treated cells than that of IgG control (Fig. 3a). It was demonstrated that anti-vimentin antibody might a binding restriction with membrane during H9N2 virus entry.
Small interference RNA (siRNA) of Vimentin reduced H9N2 virus replication

To further detect the function of vimentin in H9N2 virus reproduction, MDCK cells were pretreated with siRNA specific to vimentin, and then infected with H9N2 AIV for $36 \mathrm{~h}$. The results showed that the vimentin expressions were decreased in siRNA treated cells, compared with that of control (Fig. 3b), whose protein expressions were analyzed with grayscale analysis (Fig. 3c). Compared to control-siRNA, the protein level of vimentin was reduced to $60 \%$ in siRNA treated cells. Also, the qPCR results showed that vimentin mRNA levels in siRNA treated cells were significantly lower

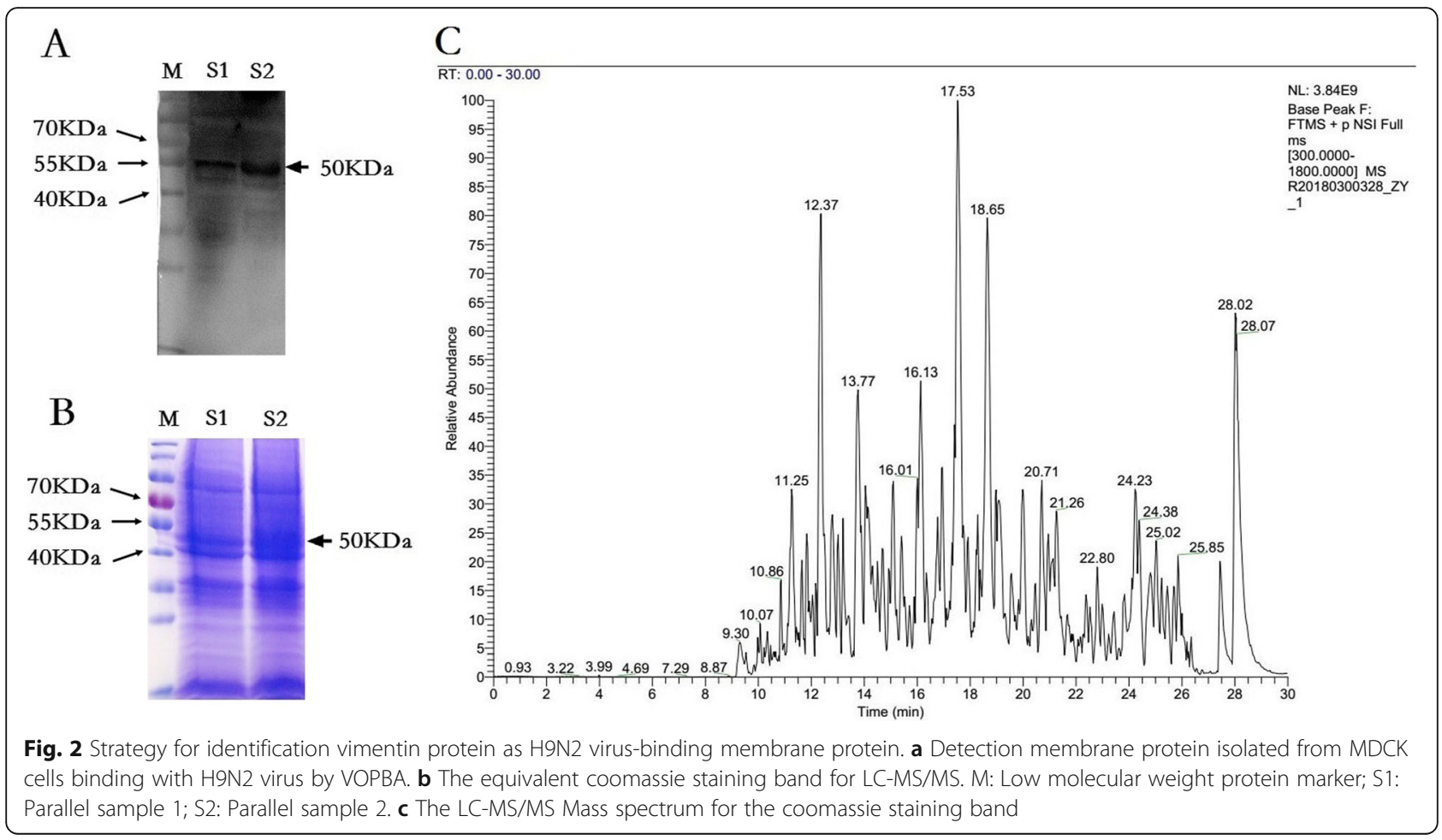


Table 6 The receptor protein binding protein sequencing analysis

\begin{tabular}{lrrrrl}
\hline & UniquePepCount & $\begin{array}{l}\text { PepCount } \\
\text { Sequence }\end{array}$ & $\begin{array}{l}\text { Cover } \\
\text { Percent }\end{array}$ & $\begin{array}{l}\text { Molecular } \\
\text { Weight }\end{array}$ & Reference \\
\hline Vimentin & 27 & 179 & $55.15 \%$ & $53,596.98$ & $\begin{array}{l}\text { tr|F1PLS4|F1PLS4_CANLF Vimentin OS=Canis lupus familiaris OX = 9615 } \\
\text { GN=VIM PE = 3 SV =1 }\end{array}$ \\
\hline
\end{tabular}

than that of control-siRNA (Fig. 3d), which were reduced to $40 \%$.

The qPCR results showed that the viral RNA levels of siRNA-transinfected group cells were 5.55 , while controlsiRNA cells were 14.45 , in which H9N2 virus replication in siRNA-transinfected group were significantly decreased, compared to that of control-siRNA (Fig. 3e). These results indicated that vimentin protein had the important role in H9N2 virus replication.

\section{Over-expressed Vimentin in MDCK cells improved H9N2 virus replication}

The $1398 \mathrm{bp}$ vimentin gene was amplified (Fig. 4a), and was inserted into the vector pcDNA-3.0 to construct the pcDNA 3.0-vimentin plasmid, which was confirmed with restriction enzyme identification (Fig. $4 \mathrm{~b})$. Also, compared with that of pcDNA-3.0 vector controls, the expressions of vimentin protein in MDCK cells transinfected with pcDNA 3.0-vimentin plasmid were significantly increased (Fig. 4c), and the mRNA levels of vimentin in pcDNA 3.0-vimentintransinfected MDCK cells were significantly increased (Fig. 4d). Furthermore, the viral RNA levels in MDCK cells transinfected with vimentin-pcDNA3.0 were significantly higher than that of pcDNA-3.0 vector controls (Fig. 4e). These results suggested that the over-expression of vimentin in MDCK cells might stimulate $\mathrm{H} 9 \mathrm{~N} 2$ virus replication.

\section{Discussion}

. Epidemiological investigation showed H9N2 subtype avian influenza virus might be the donor for the internal genes of H7N9 [8, 9] and H10N8 [10, 11]. Therefore, monitoring on molecular characteristics of H9N2 subtype AIV would be important in prevention and control on avian influenza, which play the vital role on poultry industry and human health [24]. An innovative subline naming system for AIVs was

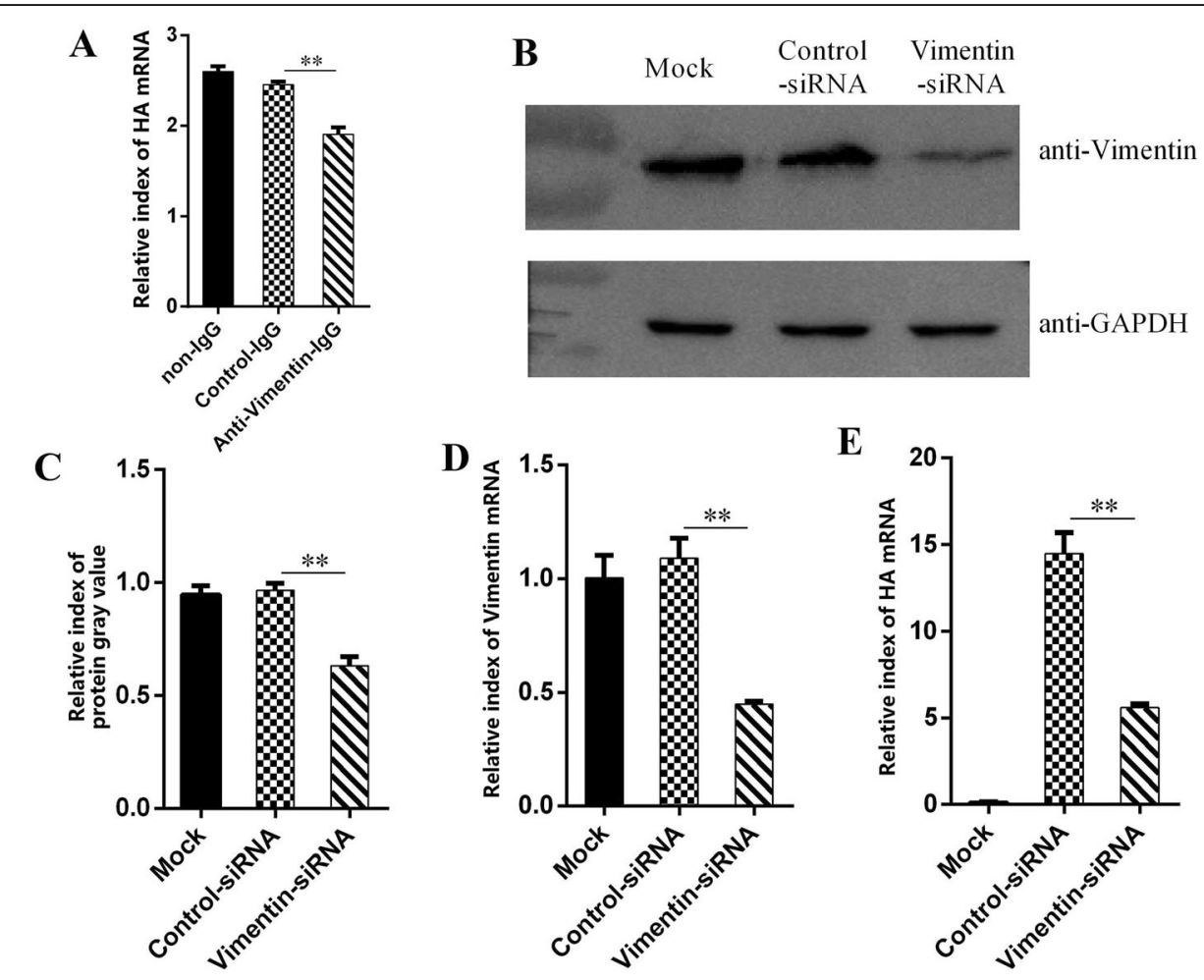

Fig. 3 Antibody and siRNA special to vimentin decreased H9N2 virus replication in MDCK cells. a Vimentin antibody inhibits H9N2 virus replication in MDCK cells. $\mathbf{b}$ siRNA decreased the expressions of vimentin by western blot. $\mathbf{c}$ Grayscale analysis of the expressions of vimentin (b). d siRNA decreased the expressions of vimentin by $\mathrm{qPCR}$. e H9N2 virus replication in MDCK cells with or without siRNA treatment. ${ }^{* *}, p<0.01$ 


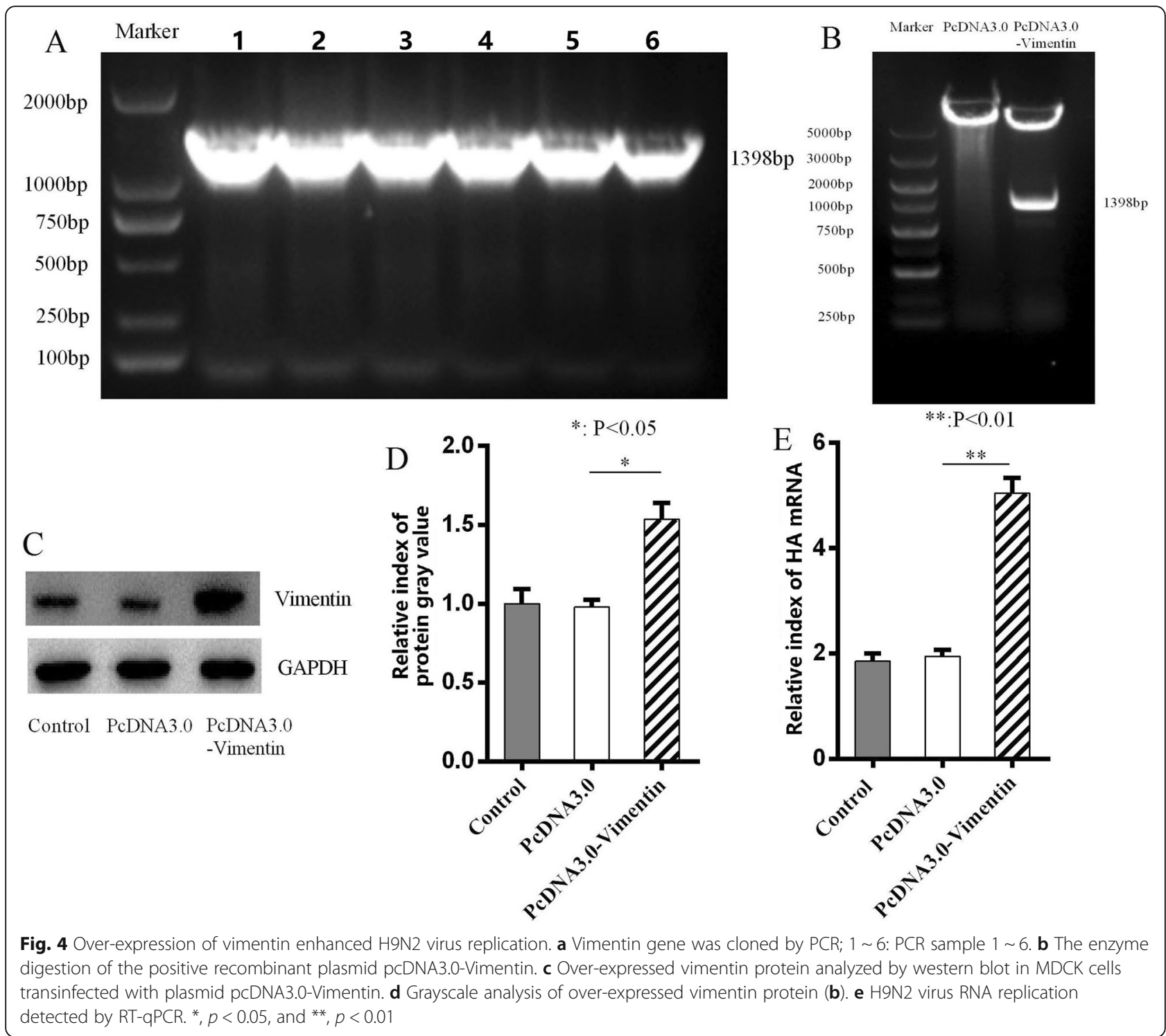

proposed, and lineages and sublineages were classified according to genetic distances, topology of the phylogenetic trees and distributions of the viruses in hosts, regions and time, including of four h9.1, h9.3, h9.4.1 and h9.4.2 subline $[5,22,25]$. In this paper, the homologies of eight gene segments of LY1 with the recent three isolates JS7, JSC1 and HBC1 suggested that LY1 might be a recent clinical common H9N2 strain. F98 and Y439 were the representative strains of $\mathrm{H} 9 \mathrm{~N} 2$ avian influenza virus belong to different subline [22, 25]. Furthermore, the NS gene of LY1 was homologous to Y439 strain (belongs to h9.3 subline), whereas other seven genes of LY1 were homologous to F98 strain (belongs to h9.4.2 subline). These results suggested that LY1 might have a potential evolutionary relationship with h9.3 and h9.4.2 subline AIV strains.
The connecting peptide of HA of LY1 was PARSSR $\downarrow G$ motif, a characteristic of H9N2 viruses of land-based poultry [8]. In this paper, there were the same receptor binding sites and seven glycosylation sites in HA genes presented among LY1, JS7, JSC1 and $\mathrm{HBC} 1$ isolates. Generally, the quantity of the glycosylation sites on HA of $\mathrm{H} 9$ viruses might be associated to the derived species, including of duck, quail and chicken [26]. The effect of these mutations of the some sites on the function of HA protein remained to be explained.

It was found that there were same hemadsorbing sites of the NA gene between that of JS7, JSC1, HBC1, and LY1, which were different from that of F98, and Y280. Unexpectedly, one amino acid mutant from NST to NNT were occurred in NA protein of 
JS7, JSC1, HBC1, but did not present in LY1. This finding suggested that the potential biological significance of this molecular marker in LY1 isolate remained to be elucidated.

The mechanism of influenza virus entry and replication in cells needs to be further investigated. In this paper, employing VOPBA and mass spectroscopy analysis, we found the vimentin might be the potential binding proteins to LY1 strain in MDCK cells. It has been reported that vimentin protein was associated with multiple cellular functions, and was required for parvoviral infection [27]. Also, vimentin protein was related with $\mathrm{pH}$-dependent infection of parvovirus, dengue virus replication and release [28, 29]. To investigate the effect of vimentin on H9N2 AIV replication, in this research, MDCK cells were treated with preincubated with anti-vimentin antibody, and then infected with H9N2 AIV. The results hinted that antivimentin antibody might has a restriction on H9N2 AIV binding and entry into MDCK cells. Also, we observed that when vimentin was knocked down with siRNA, the viral RNA levels of MDCK cells were significantly decreased, whereas the viral RNA levels of MDCK cells were significantly increased in MDCK cells with over-expressed vimentin. It was reported that vimentin was important for Epstein-Barr Virus LMP1-mediated Akt and ERK activation and transformation of rodent fibroblasts [30]. Cellular vimentin is also a specific host binding partner for $2 \mathrm{C}$ of FMDV [31], and Vimentin rearrangement plays a structural role in anchoring DENV2 to replication sites [32], and in facilitating efficient viral RNA replication with NS4A Protein [33], and in enhancing PRRSV growth by interacting with ANXA2 [34]. These results suggested that vimentin as intermediate filament in MDCK cells should be an important intracellular molecule for H9N2 virus entry and replication. Given influenza virus A may use multiple receptors for cell entry, such as $\mathrm{N}$-acetylneuraminic acid and glycolyl neuraminic acid receptors, vimentin might be used as a transport of viral vRNP during AIV replication. However, the interactions mechanism between $\mathrm{H} 9 \mathrm{~N} 2$ virus and vimentin needed to be the further research.

\section{Conclusions}

In summary, the isolated H9N2 AIV might be a recent clinical common H9N2 strain, and vimentin was identified as the binding protein to H9N2 AIV, and the results of the specific antibody, siRNA and overexpression proved that vimentin protein was one vital factor for H9N2 virus replication in MDCK cells, which might be a novel target for antiviral drug design and development.

\section{Supplementary information}

Supplementary information accompanies this paper at https://doi.org/10. 1186/s12985-020-01351-9.

Additional file 1: Table S1. The reference strains of H9N2 subtype influenza virus and their abbreviations.

Additional file 2: Table S2. Specific primers for eight gene segments of LY1 strain.

Additional file 3: Table S3. The detailed search parameters of mass analysis.

Additional file 4: Table S4. The qPCR primers for HA gene of H9N2 Virus and Vimentin.

Additional file 5: Table S5. The PCR primers of Vimentin for construction of vimentin-pcDNA3.0.

\section{Abbreviations}

AIV: Avian influenza virus; NA: Neuraminidase; HA: Hemagglutinin; EEs: Early endosomal Endosomes; Les: Late endosomal Endosomes; VRNPs: Viral ribonucleoprotein complexes; SPF: Specific pathogen free; MDCK: MadinDarbycanine kidney; DMEM: Dulbecco modified Eagle medium; FBS: Fetal bovine serum; GAPDH: Glycerophosphate dehydrogenase; NCBI: National Center for Biotechnology Information; PCR: Polymerase chain reaction; RTPCR: Reverse transcription polymerase chain reaction; VOPBA: Viral Overlay Protein Binding Assay; PAGE: Polyacrylamide gel electrophoresis;

PVDF: Polyvinylidene fluoride; MOI: Multiplicityof infection; LC-MS/MS: Liquid chromatography tandem mass spectrometry; PBS: Phosphate buffer saline;

SD: Standard deviation

\section{Acknowledgements}

We were grateful to Shanghai Zhongke Xinsheng life biotechnology company for performing the mass analysis.

\section{Authors' contributions}

Xiu Li Feng and Qing Tao Liu designed the research. Yuan Nan Yu and Yang Zheng, performed all experiments and collected data. Shan Shan Hao and Ze Zhang performed the siRNA experiments. Jia Xi Cai and Man Man Zong analyzed the data. Xiu Li Feng and Qing Tao Liu finalized the manuscript. All authors approved the content of the manuscript to be published. The funding sources had no involvement in the research work.

\section{Funding}

This work was supported by the National Key R\&D Program of China (No. 2017YFD0500706); the National Natural Science Foundation (No.31872458 and 31502100); and the Priority Academic Program Development of Jiangsu Higher Education Institutions (PAPD).

Availability of data and materials

The datasets used and analyzed during the current study are included within this article and in additional file.

Ethics approval and consent to participate Not applicable.

Consent for publication

All authors approved the content of the manuscript to be published.

Competing interests

All authors declared that they had no conflict of interest.

\section{Author details}

${ }^{1}$ Key Laboratory of Animal Microbiology of China's Ministry of Agriculture, College of Veterinary Medicine, Nanjing Agricultural University, Nanjing 210095, China. ${ }^{2}$ Institute of Veterinary Medicine, Jiangsu Academy of Agricultural Sciences, Nanjing 210014, China. ${ }^{3}$ MOE Joint International Research Laboratory of Animal Health and Food Safety, College of Veterinary Medicine, Nanjing Agricultural University, Nanjing 210095, China. 
Received: 18 December 2019 Accepted: 8 June 2020

Published online: 17 June 2020

\section{References}

1. Wu Y, Lin J, Yang S, Xie Y, Wang M, Chen X, Zhu Y, Luo L, Shi W. The molecular characteristics of avian influenza viruses (H9N2) derived from air samples in live poultry markets. Infect Genet Evol. 2018;60:191-6.

2. Zeng X, Liu M, Zhang H, Wu J, Zhao X, Chen W, Yang L, He F, Fan G, Wang $D$, et al. Avian influenza H9N2 virus isolated from air samples in LPMs in Jiangxi, China. Virol J. 2017;14(1):136.

3. Liu Q, Chen H, Huang J, Chen Y, Gu M, Wang X, Hu S, Liu X, Liu X. A nonpathogenic duck-origin H9N2 influenza a virus adapts to high pathogenicity in mice. Arch Virol. 2014;159(9):2243-52.

4. Zhu Y, Hu S, Bai T, Yang L, Zhao X, Zhu W, Huang Y, Deng Z, Zhang H, Bai $Z$, et al. Phylogenetic and antigenic characterization of reassortant H9N2 avian influenza viruses isolated from wild waterfowl in the east Dongting Lake wetland in 2011-2012. Virol J. 2014;11:77.

5. Lu JH, Liu XF, Shao WX, Liu YL, Wei DP, Liu HQ. Phylogenetic analysis of eight genes of H9N2 subtype influenza virus: a mainland China strain possessing early isolates' genes that have been circulating. Virus Genes. 2005;31(2):163-9.

6. Xia J, Cui JQ, He X, Liu YY, Yao KC, Cao SJ, Han XF, Huang Y. Genetic and antigenic evolution of H9N2 subtype avian influenza virus in domestic chickens in southwestern China, 2013-2016. PLoS One. 2017;12(2):e0171564.

7. Li Y, Liu M, Sun Q, Zhang H, Zhang H, Jiang S, Liu S, Huang Y. Genotypic evolution and epidemiological characteristics of H9N2 influenza virus in Shandong Province, China. Poult Sci. 2019;98(9):3488-95.

8. Lam TT, Wang J, Shen Y, Zhou B, Duan L, Cheung CL, Ma C, Lycett SJ, Leung CY, Chen X, et al. The genesis and source of the H7N9 influenza viruses causing human infections in China. Nature. 2013;502(7470):241-4

9. Chen E, Chen Y, Fu L, Chen Z, Gong Z, Mao H, Wang D, Ni MY, Wu P, Yu Z, et al. Human infection with avian influenza $A(\mathrm{H} 7 \mathrm{~N} 9)$ virus re-emerges in China in winter 2013. Euro Surveill. 2013;18(43):20616.

10. Chen H, Yuan H, Gao R, Zhang J, Wang D, Xiong Y, Fan G, Yang F, Li X, Zhou J, et al. Clinical and epidemiological characteristics of a fatal case of avian influenza a H10N8 virus infection: a descriptive study. Lancet. 2014; 383(9918):714-21.

11. Li X, Shi J, Guo J, Deng G, Zhang Q, Wang J, He X, Wang K, Chen J, Li Y, Fan $J$, et al. Genetics, receptor binding property, and transmissibility in mammals of naturally isolated H9N2 avian influenza viruses. PLoS Pathog. 2014;10(11): e1004508.

12. Matrosovich MN, Krauss S, Webster RG. H9N2 influenza a viruses from poultry in Asia have human virus-like receptor specificity. Virology. 2001; 281(2):156-62.

13. Ha Y, Stevens DJ, Skehel JJ, Wiley DC. X-ray structures of H5 avian and H9 swine influenza virus hemagglutinins bound to avian and human receptor analogs. Proc Natl Acad Sci U S A. 2001;98(20):11181-6.

14. Wang J, Wu M, Hong W, Fan X, Chen R, Zheng Z, Zeng Y, Huang R, Zhang Y, Lam TT, Smith DK, Zhu H, Guan Y. Infectivity and transmissibility of avian H9N2 influenza viruses in pigs. J Virol. 2016;90(7):3506-14.

15. Styers ML, Salazar G, Love R, Peden AA, Kowalczyk AP, Faundez V. The endo-lysosomal sorting machinery interacts with the intermediate filament cytoskeleton. Mol Biol Cell. 2004;15(12):5369-82.

16. Harrison SC. Viral membrane fusion. Virology. 2015;479-480:498-507.

17. Liu Q, Liu Y, Yang J, Huang X, Han K, Zhao D, Bi K, Li Y. Two genetically similar H9N2 influenza a viruses show different pathogenicity in mice. Front Microbiol. 2016;7:1737.

18. Liu Q, Huang J, Chen Y, Chen H, Li Q, He L, Hao X, Liu J, Gu M, Hu J, et al. Virulence determinants in the PB2 gene of a mouse-adapted H9N2 virus. J Virol. 2015;89(1):877-82.

19. Eriksson $P$, Lindskog C, Lorente-Leal V, Waldenström J, González-Acuna D, Järhult JD, Lundkvist $\AA$, Olsen B, Jourdain E, Ellström P. Attachment patterns of human and avian influenza viruses to trachea and Colon of 26 bird species - support for the community concept. Front Microbiol. 2019;10:815.

20. Eriksson $P$, Lindskog C, Engholm E, Blixt O, Waldenström J, Munster V, Lundkvist $\AA$, Olsen B, Jourdain E, Ellström P. Characterization of avian influenza virus attachment patterns to human and pig tissues. Sci Rep. 2018; $8(1): 12215$.

21. Kim M, Yu JE, Lee JH, Chang BJ, Song CS, Lee B, Paik DJ, Nahm SS. Comparative analyses of influenza virus receptor distribution in the human and mouse brains. J Chem Neuroanat. 2013;52:49-57.
22. Liu S, Ji K, Chen J, Tai D, Jiang W, Hou G, Chen J, Li J, Huang B. Panorama phylogenetic diversity and distribution of type a influenza virus. PLoS One. 2009;4(3):e5022.

23. Feng $X L$, Zheng $Y$, Zong MM, Hao SS, Zhou GF, Cao RB, Chen PY, Liu TQ. The immunomodulatory functions and molecular mechanism of a new bursal heptapeptide (BP7) in immune responses and immature B cells. Vet Res. 2019;50(1):64. https://doi.org/10.1186/s13567-019-0682-7.

24. Sun Y, Liu J. H9N2 influenza virus in China: a cause of concern. Protein Cell. 2015;6(1):18-25.

25. Xu KM, Smith GJ, Bahl J, Duan L, Tai H, Vijaykrishna D, Wang J, Zhang JX, Li KS, Fan XH, Webster RG, Chen H, Peiris JS, Guan Y. The genesis and evolution of H9N2 influenza viruses in poultry from southern China, 2000 to 2005. J Virol. 2007:81(19):10389-401.

26. Perez DR, Lim W, Seiler JP, Yi G, Peiris M, Shortridge KF, Webster RG. Role of quail in the interspecies transmission of $\mathrm{H} 9$ influenza a viruses: molecular changes on HA that correspond to adaptation from ducks to chickens. J Virol. 2003;77(5):3148-56

27. Fay $N$, Nelly $P$. The intermediate filament network protein, vimentin, is required for parvoviral infection. Virology. 2013;444(1-2):181-90.

28. Kanlaya R, Pattanakitsakul SN, Sinchaikul S, Chen ST, Thongboonkerd V. Vimentin interacts with heterogeneous nuclear ribonucleoproteins and dengue nonstructuralprotein 1 and is important for viral replication and release. Mol BioSyst. 2010;6(5):795-806.

29. Ros C, Burckhardt CJ, Kempf C. Cytoplasmic trafficking of minute virus of mice: low-pH requirement, routing to late endosomes, and proteasome interaction. J Virol. 2002;76(24):12634-45.

30. Meckes DG Jr, Menaker NF, Raab-Traub N. Epstein-Barr virus LMP1 modulates lipid raft microdomains and the vimentin cytoskeleton for signal transduction and transformation. J Virol. 2013;87(3):1301-11.

31. Gladue DP, O'Donnell V, Baker-Branstetter R, Holinka LG, Pacheco JM, Fernández Sainz I, Lu Z, Ambroggio X, Rodriguez L, Borca MV. Foot-andmouth disease virus modulates cellular vimentin for virus survival. J Virol. 2013;87(12):6794-803.

32. Lei S, Tian YP, Xiao WD, Li S, Rao XC, Zhang JL, Yang J, Hu XM, Chen W. ROCK is involved in vimentin phosphorylation and rearrangement induced by dengue virus. Cell Biochem Biophys. 2013;67(3):1333-42.

33. Teo CS, Chu JJ. Cellular vimentin regulates construction of dengue virus replication complexes through interaction with NS4A protein. J Virol. 2014; 88(4):1897-913.

34. Chang XB, Yang YQ, Gao JC, Zhao K, Guo JC, Ye C, Jiang CG, Tian ZJ, Cai $\mathrm{XH}$, Tong GZ, An TQ. Annexin A2 binds to vimentin and contributes to porcine reproductive and respiratory syndrome virus multiplication. Vet Res. 2018:49(1):75.

\section{Publisher's Note}

Springer Nature remains neutral with regard to jurisdictional claims in published maps and institutional affiliations.

Ready to submit your research? Choose BMC and benefit from:

- fast, convenient online submission

- thorough peer review by experienced researchers in your field

- rapid publication on acceptance

- support for research data, including large and complex data types

- gold Open Access which fosters wider collaboration and increased citations

- maximum visibility for your research: over $100 \mathrm{M}$ website views per year

At BMC, research is always in progress.

Learn more biomedcentral.com/submissions 